\title{
Therapies for tuberculosis and AIDS: myeloid-derived suppressor cells in focus
}

\author{
Anca Dorhoi, ${ }^{1,2}$ Leigh A. Kotzé, ${ }^{3,4,5}$ Jay A. Berzofsky, ${ }^{6}$ Yongjun Sui, ${ }^{6}$ Dmitry I. Gabrilovich, ${ }^{7}$ Ankita Garg, ${ }^{8}$ Richard Hafner, ${ }^{9}$ \\ Shabaana A. Khader, ${ }^{10}$ Ulrich E. Schaible, ${ }^{11,12,13}$ Stefan H.E. Kaufmann, ${ }^{14,15}$ Gerhard Walzl, ${ }^{3,4,5}$ Manfred B. Lutz, ${ }^{16}$ Robert N. Mahon, ${ }^{17}$ \\ Suzanne Ostrand-Rosenberg, ${ }^{18}$ William Bishai, ${ }^{19}$ and Nelita du Plessis $3,4,5$ \\ IInstitute of Immunology, Friedrich-Loeffler-Institute, Greifswald-Insel Riems, Germany. ${ }^{2}$ Faculty of Mathematics and Natural Sciences, University of Greifswald, Greifswald, Germany. ${ }^{3}$ Centre for Tuberculosis \\ Research, South African Medical Research Council, Cape Town, South Africa. ${ }^{4}$ DST-NRF Centre of Excellence for Biomedical Tuberculosis Research (CBTBR) and ${ }^{5}$ Division of Molecular Biology and Human \\ Genetics, Faculty of Medicine and Health Sciences, Stellenbosch University, Cape Town, South Africa. ${ }^{6}$ Vaccine Branch, Center for Cancer Research, National Cancer Institute, NIH, Bethesda, Maryland, \\ USA. 'Wistar Institute, Philadelphia, Pennsylvania, USA. ${ }^{8}$ Department of Infectious Diseases, University of Georgia, Athens, Georgia, USA. ${ }^{9}$ Division of AIDS, National Institute of Allergy and Infectious \\ Diseases, NIH, Bethesda, Maryland, USA. ${ }^{10}$ Department of Molecular Microbiology, Washington University in St. Louis, St. Louis, Missouri, USA. "Cellular Microbiology, Priority Program Infections, ${ }^{12 T h e m a t i c}$ \\ Translation Unit Tuberculosis, German Center for Infection Research, and ${ }^{3}$ Leibniz Research Alliance INFECTIONS'21, Research Center Borstel, Borstel, Germany. ${ }^{14}$ Max Planck Institute for Infection Biology, \\ Berlin, Germany. ${ }^{15} \mathrm{Hagler}$ Institute for Advanced Study, Texas A\&M University, College Station, Texas, USA. ${ }^{16 I n s t i t u t e ~ f o r ~ V i r o l o g y ~ a n d ~ I m m u n o b i o l o g y, ~ U n i v e r s i t y ~ o f ~ W u ̈ r z b u r g, ~ W u ̈ r z b u r g, ~ G e r m a n y . ~}{ }^{17}$ Division \\ of AIDS, Columbus Technologies \& Services Inc., Contractor to National Institute of Allergy and Infectious Diseases, NIH, Bethesda, Maryland, USA. ${ }^{18}$ Department of Pathology and Huntsman Cancer \\ Institute, University of Utah, Salt Lake City, Utah, USA. ${ }^{19}$ Center for Tuberculosis Research, Johns Hopkins School of Medicine, Baltimore, Maryland, USA.
}

The critical role of suppressive myeloid cells in immune regulation has come to the forefront in cancer research, with myeloidderived suppressor cells (MDSCs) as a main oncology immunotherapeutic target. Recent improvement and standardization of criteria classifying tumor-induced MDSCs have led to unified descriptions and also promoted MDSC research in tuberculosis (TB) and AIDS. Despite convincing evidence on the induction of MDSCs by pathogen-derived molecules and inflammatory mediators in TB and AIDS, very little attention has been given to their therapeutic modulation or roles in vaccination in these diseases. Clinical manifestations in TB are consequences of complex host-pathogen interactions and are substantially affected by HIV infection. Here we summarize the current understanding and knowledge gaps regarding the role of MDSCs in HIV and Mycobacterium tuberculosis (co)infections. We discuss key scientific priorities to enable application of this knowledge to the development of novel strategies to improve vaccine efficacy and/or implementation of enhanced treatment approaches. Building on recent findings and potential for cross-fertilization between oncology and infection biology, we highlight current challenges and untapped opportunities for translating new advances in MDSC research into clinical applications for TB and AIDS.

Innate suppressor cells in cancer, tuberculosis, and AIDS

Immunosuppressive myeloid cells were originally described in tumor-bearing mice (1) and cancer patients (2) as pathologically activated or atypical myeloid cells. As this field expanded, requirements for a common nomenclature emerged, and a terminology for classifying myeloid-derived suppressor cells (MDSCs) was adapted (3). The defining characteristic of MDSCs is suppression of T cell activation and function (4). Before their identification in malignancies, "natural suppressor" cells were reported in systemic mycobacterial infection (5). More recently, increased MDSC numbers and activity have been identified in tuberculosis (TB) and AIDS patients (6-8).

Solid tumors and lesions in chronic infections share multiple features, including hypoxia, neovascularization, tissue remodeling, and nonresolved inflammation, which shape the cellular landscape

Conflict of interest: WB holds shares in Sonoval, which is commercializing an improved version of denileukin diftitox.

Copyright: (c) 2020, American Society for Clinical Investigation.

Reference information: J Clin Invest. 2020;130(6):2789-2799.

https://doi.org/10.1172/JCl136288. of such lesions (Figure 1). Chronic, low-grade inflammation induces and activates MDSCs (9). Primary HIV infection is associated with elevated inflammatory mediators, e.g., serum GM-CSF (10) and IL-6 (11), which are drivers of MDSCs. Host responses in cancer, $\mathrm{TB}$, and AIDS are often marked by immune suppression. Indeed, MDSCs in individuals with TB and AIDS impair CD4 $4^{+}$and $\mathrm{CD}^{+} \mathrm{T}$ cell proliferation, function, and trafficking $(6-8,12)$, all hallmarks of tumor-induced MDSC immunosuppressive mechanisms. MDSCs also facilitate Treg development that further amplifies immune suppression (11, 13-15). Since overexuberant immune suppression restrains effective immunity, understanding how MDSCs impact TB and AIDS is a critical priority. Lessons learned from oncology may inform drug targeting of MDSCs in therapies for TB and AIDS (16). Recognizing this potential, the National Institute of Allergy and Infectious Diseases in January 2019 convened a workshop called Suppressor Cells and TB/HIV: What Is Known and What Can Be Learned to bring together leaders in MDSC research from both TB/HIV and oncology. This Review identifies the gaps that hamper translation of MDSC knowledge into effective intervention strategies, and emphasizes how cross-fertilization between cancer and infection fields could bolster TB and AIDS therapies. 
A TME

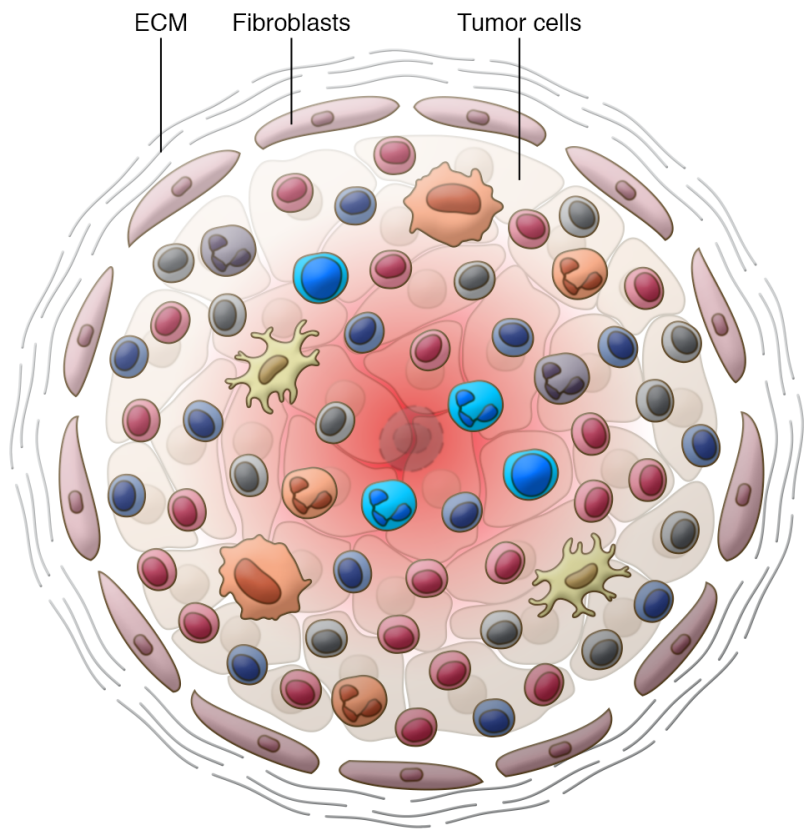

B TB granuloma microenvironment
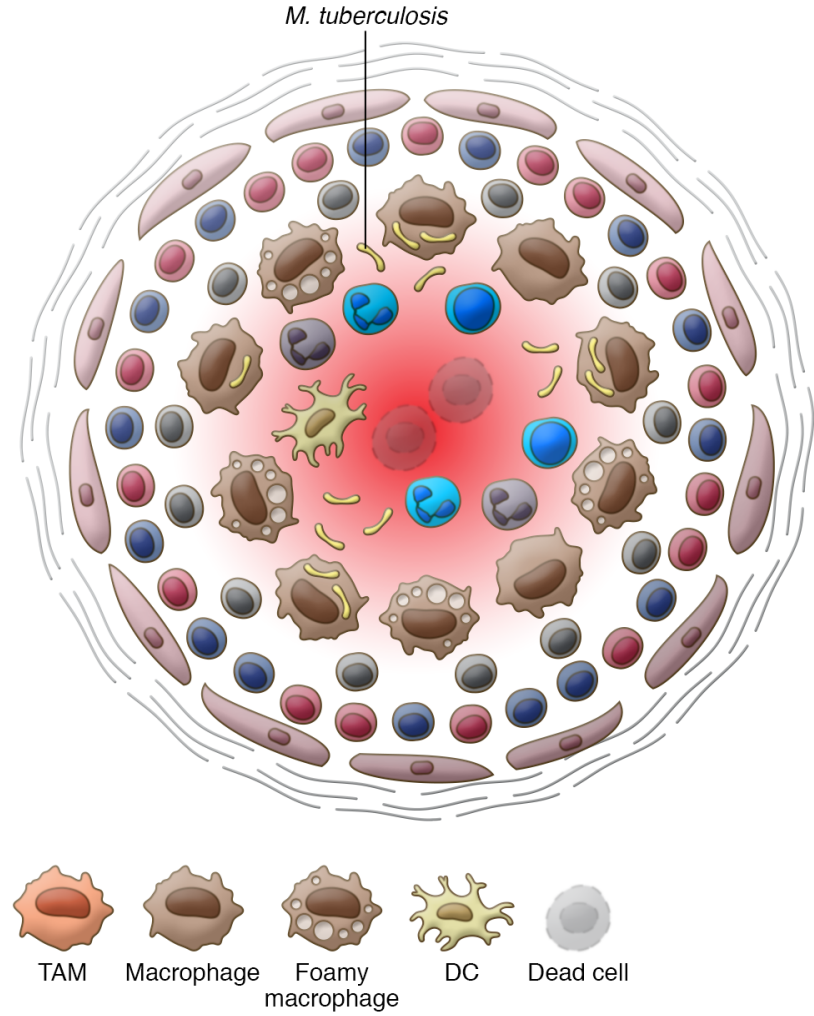

$\mathrm{O}_{2}$

Figure 1. A schematic view of TB MDSCs and tumor MDSCs within the cellular architecture of the typical granuloma or tumor microenvironment. The figure compares MDSCs in (A) the solid TME and (B) the TB granuloma microenvironment. M. tuberculosis infects various innate immune cells including macrophages and neutrophils within the granuloma. Macrophages might polarize and differentiate to form foam and multinucleated cells, whose presence is most frequently at the center of mature TB granulomas. Other myeloid cells include DCs that together form the core of the granuloma. Recruited NK cells, B cells, and T cells, including Th1, Th2, and Th17 cells, Tregs, and CD8 ${ }^{+}$T cells, form the outer cuff, often surrounded by fibroblasts and a collagen matrix (extracellular matrix [ECM]). The type, combination, phenotypes, and arrival timing of immune cells influence pathogen containment and the trajectory of granuloma development. Immune cells produce a range of soluble effector molecules such as cytokines and chemokines. In this inflammatory environment, advanced granulomas develop hypoxia and necrosis, which are followed by tissue destruction. The presence of MDSCs has been reported in necrotic TB granulomas. Similar cellular constituents and crosstalk have been reported for the TME. Apart from malignant cells, the TME contains immune cells, including TAMs and TANs, DCs, NK cells, and T cells, often surrounded by the stroma of fibroblasts and ECM. Both tumor and immune cells produce inflammatory and suppressive signaling molecules such as growth factors, cytokines, chemokines, etc. Tumor-derived immunosuppressive mechanisms are well described, including the presence of MDSCs.

\section{Obstacles to MDSC targeting in TB and AIDS}

To date, no drug directly targeting MDSCs has received FDA approval; however, many compounds have demonstrated success in preclinical models of cancer and in clinical trials (17). Some of these compounds have shown promise in preclinical TB studies (17). Despite this potential, it remains unknown whether MDSCs would have a clinically relevant impact on the course of HIV/TB disease or affect treatment outcome in humans. To answer this question, the TB and HIV fields require information on MDSC abundance in various immune compartments and throughout therapy, specifically from trials investigating disease relapse or treatment response, to justify prioritization of MDSC-based interventions as an immunomodulatory option. In the following, we address misconceptions and obstacles that have restricted MDSC research in infectious diseases.

\section{Identification and monitoring}

MDSCs in TB and AIDS versus cancer. Murine MDSCs comprise monocytic (M-MDSC) and polymorphonuclear (PMN-MDSC)

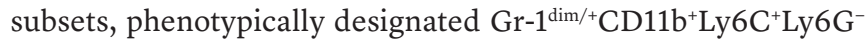
and $\mathrm{Gr}-1^{\mathrm{dim} /{ }^{+}} \mathrm{CD} 11 \mathrm{~b}^{+} \mathrm{Ly} 6 \mathrm{C}^{\mathrm{lo}} \mathrm{Ly} 6 \mathrm{G}^{+}$, respectively (3, 18, 19). Human corresponding subtypes in the peripheral blood mononuclear fraction bear the phenotype $\mathrm{CD} 11 \mathrm{~b}^{+} \mathrm{CD} 14^{+} \mathrm{CD} 15^{-}$and

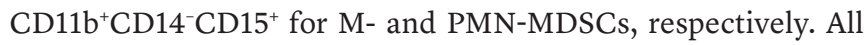
human MDSCs are HLA-DR ${ }^{-/ 10}$, while immature MDSC progenitor populations (early-stage MDSCs, or e-MDSCs) are $\mathrm{Lin}^{-}$and CD33+hit Identification of eosinophilic MDSCs (Eo-MDSCs) in mice infected with Staphylococcus aureus expanded the family of suppressive granulocytes (20). In cancer studies, the markers CD66b and S100A9 were originally included to define PMN-MDSCs and M-MDSCs, respectively, and subsequently 


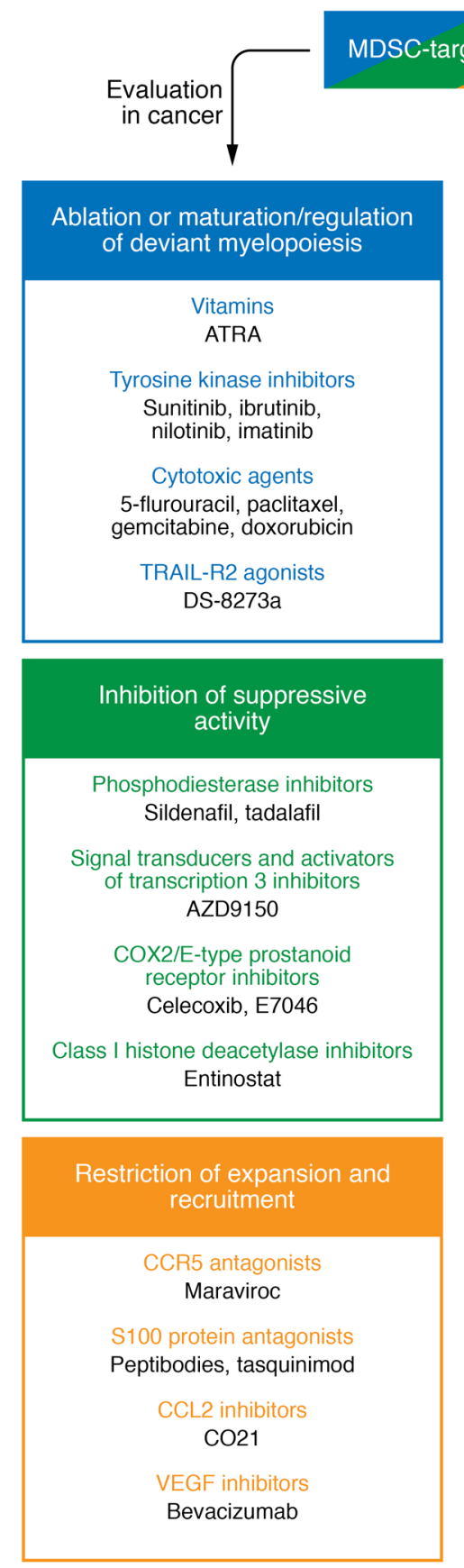

Figure 2. Drugs targeting MDSCs in cancer and tested in TB. Various classes of compounds target three main biological processes linked to MDSCs in oncology, notably genesis, dynamics, and suppressive functions. Depicted drugs have reached clinical trials in patients with cancer and been validated for their effects on MDSCs. Few compounds have been tested in animal models of TB (gray boxes). The compounds in the lower gray box have been tested as immunotherapeutics in TB; however, their effects on MDSCs have not been evaluated.

also shown to be expressed by TB-induced MDSCs (4, 21-23). Markers recently assigned to MDSCs, such as $\operatorname{LOX1}(24,25)$ and FATP2 (26), await validation in infection. Differences in subtype reporting highlight the importance of defining unequivocal phenotypic MDSC markers, or alternatively reaching a consensus for the MDSC phenotype reporting across infectious diseases, as achieved for cancer (22).
Application of uniform phenotypic analyses reveals that ratios of MDSC subsets differ among various cancer types (27-29); e.g., in selected malignancies, PMN-MDSC frequencies are up to 1.5 times higher in blood and even higher at the tumor site relative to those in healthy individuals $(24,30$, 31). Expansion of e- and M-MDSCs occurs in some cancers (32-34), and in TB patients M-MDSCs are the major circulating subset, reaching $4 \%$ to $10 \%$ of the PBMC fraction, while PMN-MDSC frequencies of up to $30 \%$ of total PBMCs have been reported $(6,7)$. MDSC abundances in granulomas specifically are largely unknown, owing to the inaccessibility of the lung compartment (see Migration/trafficking of MDSCs to lungs in TB).

Equally confounding are the reports on MDSC subsets in AIDS. PMN-MDSC levels of up to $5 \%$ of total PBMCs have been observed in primary HIV infection and up to $8 \%$ in chronic HIV infection $(7,10,12)$, while remaining undetectable in healthy adults. M-MDSC levels of up to $4 \%$ of total PBMCs compared with $1 \%$ in healthy controls have also been reported in HIV infected adults, despite their use of efficacious antiretroviral therapy (HAART) (12). Irrespective of subset prevalence, MDSCs positively correlate with viral load, negatively correlate with $\mathrm{CD} 4^{+} \mathrm{T}$ cell count, and may decrease subsequent to HAART $(10,12$, 28). Post-HAART residual immune activation potentially supports MDSC genesis, so that monitoring of MDSC frequencies may serve as an indicator of treatment-induced immune dysfunction.

Tumor burden and disease stage modulate subset ratios $(28,35,36)$, prompting the exploitation of MDSCs as diagnostic and predictive biomarkers in oncology. Accordingly, distinct treatment approaches may be required, depending on the most prevalent subset (37-42). Similar scenarios are envisaged for TB and AIDS. A direct correlation between MDSC frequency and infection phase and duration has been suggested for TB patients (7). However, inconsistent criteria used to classify MDSCs may have resulted in their misclassification as typical myeloid cells in other studies (43-45). This, along with insufficient clinical TB disease burden/stage classification, has likely resulted in underreporting of MDSCs and disparities in reported frequencies of MDSCs in TB. Large-scale studies of MDSC subsets across the spectrum of TB and AIDS, with long-term follow-up, particularly in TB patients, are overdue for accurate correlation of MDSCs to relapse or treatment failure. 
MDSCs in vaccination. Apart from altering host protective responses in TB and AIDS, MDSCs may also weaken the efficacy of prophylactic or therapeutic vaccines. In cancer, efficacy of antineoplastic agents increases when they are used in conjunction with MDSC inhibitors (34, 46-48). Unbalanced immunoregulatory mechanisms could underlie anti-TB vaccine failures (49), and in this context, the role of MDSCs needs to be explored. A TB vaccine superior to bacille Calmette-Guérin (BCG) is still not available $(50,51)$. BCG induces MDSCs in mice (52), and immunizations with heat-killed and dried Mycobacterium tuberculosis in mineral oil (complete Freund's adjuvant [CFA]) (53) hamper immune activation. This is not observed with incomplete Freund's adjuvant (IFA; used as Montanide ISA51 IFA in humans), which lacks mycobacterial components (54). CFA causes splenic accumulation of MDSCs, which deplete DCs by an NO-dependent mechanism without directly affecting $\mathrm{T}$ cells (55). CFA immunization cannot be extrapolated to humans, yet these data call for investigation of MDSCs in vaccine failure versus success. Adjunctive therapies along with $\mathrm{TB}$ vaccination to counteract the generation or suppressive functions of MDSCs need to be explored (50, 56-58). BCG is delivered prophylactically to neonates, and the increase in MDSCs during pregnancy (59), and in newborns (59), suggests that preventive vaccination should consider MDSC modulation. Postexposure vaccination should also consider MDSCs as adjunct targets. MDSCs suppress NK cell responses, potentially influencing the efficacy/durability of currently used BCG or revaccination strategies. Vaccine trials do not routinely monitor MDSCs, and their inclusion may aid in vaccine development. Few studies and no TB vaccine trials have examined the role of MDSCs in memory $\mathrm{CD}^{+} \mathrm{T}$ cell or "polyfunctional" responses. This is an area of potential discovery and innovation, as BCG is increasingly recognized for its nonspecific effects, notably protection from heterogeneous pathogens (60).

In an HIV/SIV macaque model, an AIDS vaccine induced MDSCs that inhibited or weakened vaccine immunogenicity and protection (61). MDSCs induced by this vaccine, HIV/SIV infection, or viral proteins (11-14) equally suppressed $\mathrm{T}$ cell proliferation in vitro (61). Another HIV/SIV vaccine study achieved $44 \%$ vaccine efficacy while both PMN- and M-MDSC subsets were induced, the former mostly late in the vaccination regimen (62). MDSCs function as a double-edged sword in SIV vaccination and infection in nonhuman primate (NHP) models (63): MDSCs can be induced by vaccines, dampen vaccine efficacy, promote viral transmission, and also become infected with SIV to serve as a viral reservoir. However, MDSCs in SIV infection reduce $\mathrm{CD} 4^{+} \mathrm{T}$ cell activation and thus reduce viral load by curtailing cell-cell transmission.

MDSC inhibition or elimination strategies. Considering that the pathophysiological characteristics of the tumor microenvironment (TME) include $\mathrm{CD}^{+} \mathrm{T}$ cells as the principal effector mechanism against tumor cells, the most likely clinically feasible MDSC-targeting strategy in oncology would be as an adjunct treatment to potentiate cancer therapies aimed at improving $\mathrm{CD} 8^{+}$ responses. In TB, myeloid cells function as pathogen niche as well as effectors in the granuloma, having the ultimate responsibility of killing intracellular mycobacteria upon proper activation. Targeting myeloid cells, such as MDSCs, is thus likely to have a much larger impact on disease outcome in TB than in cancer.
Several therapeutic strategies under investigation for TB are aimed at pharmacological modification of (a) MDSC expansion, activation, and recruitment; (b) differentiation of MDSCs into mature myeloid cells; (c) inhibition of molecular mechanisms of action; or (d) depletion of MDSCs at inflammatory sites (Figure 2).

Chemotherapy in cancer patients generally suppresses innate and adaptive immunity. Selected drugs at lower doses paradoxically stimulate $\mathrm{T}$ cell responses, suggesting putative interference with MDSC-mediated T cell suppression. Gemcitabine and 5-fluorouracil enhance antitumor immunity by depleting MDSCs (64-67). These drugs also promote immune defense against $S$. aureus infections in mice (68). However, neither drug is unequivocally advantageous for reduction of MDSC activity. Both can have reverse effects when MDSCs release cathepsin B, subsequently triggering NLRP3 inflammasome activation and thereby enhancing MDSC activity (69). Similarly, gemcitabine-mediated MDSC depletion has been shown to exacerbate Nippostrongylus brasiliensis or Trichinella spiralis infection in mice, presumably by enhancing mast cell responses (70). Thus, when and how gemcitabine can act as a suppressor of MDSC development and function requires further investigation. It also remains to be validated whether encapsulation of gemcitabine would improve its effects on MDSCs (71).

Tyrosine kinase inhibitors, such as sunitinib, showed suppression of MDSCs in several studies (72-74), but failed in another murine tumor model in which, instead, nilotinib, dasatinib, and sorafenib successfully suppressed MDSCs (74). Additional mechanistic studies will clarify how these drugs affect MDSCs and their potential as TB host-directed therapies (HDTs). Other compounds reduce MDSC numbers in mice and humans and promote generation of immunogenic DC-like cells, both events presumably beneficial for TB vaccination $(75,76)$.

Carboplatin and cisplatin are both used in cancer treatments and also target MDSCs; the antitumoral efficacy and adverse effects exhibited by cisplatin are higher than those shown by carboplatin. Carboplatin and paclitaxel treatment combined with a peptide vaccine in Montanide adjuvant appeared to increase frequencies of $\mathrm{Gr}-\mathrm{I}^{\mathrm{lo}} \mathrm{CD} 11 \mathrm{~b}^{+}$cells in blood and promote $\mathrm{T}$ cell immunity in a murine HPV16 tumor model as well as in patients with cervical cancer, but spared or reduced the frequencies of $\mathrm{Gr}-1^{\mathrm{hi}} \mathrm{CD} 11 \mathrm{~b}^{+}$ granulocytic cells and $\mathrm{Gr}-\mathrm{1}^{-} \mathrm{CD} 11 \mathrm{~b}^{+}$monocytes (77, 78). Since pre-neutrophils downregulate the Gr-1/Ly6G epitopes during proliferation in vitro (79), it requires clarification whether $\mathrm{Gr}-1^{\text {lo }}$ cell loss and $\mathrm{Gr}-\mathrm{1}^{\text {hi }}$ cell gain in these in vivo studies are due to depletion or a shift in surface expression with acquisition of altered functions. In one study, cisplatin treatment was found to increase Ly6C $\mathrm{Ch}^{\mathrm{hi}}$ and CD11 ${ }^{\text {hi }}$ cells with elevated costimulatory activity through CD70/ CD80/CD86 molecules and better $\mathrm{CD}^{+} \mathrm{T}$ cell responses (78), indicating that cisplatin treatment generated monocyte-derived DCs by interfering with the function of MDSCs without depleting them. The additional combination of cisplatin/radiotherapy with cyclophosphamide (CTX) plus an inducible NO synthase (NOS2) inhibitor further affected MDSCs and improved immune responses and clinical responses in otherwise radiotherapy-resistant tumors (80). These have not yet been tested in TB and AIDS.

All-trans retinoic acid (ATRA) reduces M-MDSC frequencies in tumor-bearing mice (81) and cancer patients (82), along with increases in antigen-presenting cells (83). ATRA interferes with 
oxidative processes in MDSCs (84), affecting PMN-MDSCs as major ROS producers $(85,86)$. ATRA, alone or in combination with antibiotics, minimizes TB relapse in a mouse model and lowers bacillary burdens, likely providing partial clarification of the protective effect of this compound $(87,88)$. Additional MDSC-targeting drugs tested in oncology, such as PDE5 inhibitors and imatinib, improved TB outcome in mouse models; however, a direct link to MDSCs has not been established. Many other MDSC-targeting approaches have shown promise in cancer (76-78) and are described extensively elsewhere (17). Additional combination approaches for the future include MDSC-based interventions with checkpoint inhibitors and activators of costimulatory receptor signaling, e.g., OX-40 and TLRs. Approaches using combinations of above-mentioned therapies/strategies could be explored in TB/ HIV, as these may be synergistically effective.

Taken together, experimental evidence suggests that BCG, $M$. tuberculosis-derived vaccine components, and SIV vaccines could induce MDSCs. Drug modulation of MDSCs may thus improve efficacy of BCG as well as novel vaccine candidates. Opportunities for modulating MDSCs as HDT for active TB have not been substantially explored and deserve more attention.

\section{Genesis and suppressive functions}

Epigenetic and posttranslational modification of MDSCs in TB/ HIV. M. tuberculosis and HIV contain structural moieties that trigger MDSC generation. These include mycobacterial glycolipids (89), HIV gp120 (11), and/or Tat proteins (14). TLR2 and TLR4 receptors predominantly induce M-MDSCs $(11,90)$, while host factors generated during infection contribute to MDSC expansion in both diseases.

Epigenetic signatures and fate mapping of MDSCs in TB and HIV infection remain poorly defined. Cancer studies suggest that peripheral MDSC proliferation is unlikely, and rather medullary and extramedullary compartments serve as sites of MDSC development or activation $(24,91,92)$. This implies that MDSCs in TB and HIV infection may expand either from fully differentiated monocytes or granulocytes or from myeloid precursors. The two-step activation process described for M-MDSCs comprising GM-CSF/IFN- $\gamma /$ AKT pathways (79) remains to be validated. In cancer, MDSCs are epigenetically regulated through DNA methylation by histone deacetylase-2 (HDAC2), a negative regulator of tumor MDSC expansion and function (93), and covalent histone modifications (94-98). Other cancer studies convincingly show that the accumulation of histone H3 lysine 27 acetylation (H3K27ac), an enhancer histone modification, is involved in MDSC generation (95). Thus, epigenetic modification could be exploited as a specific and effective cancer treatment strategy. Although the MDSC epigenetic profile remains to be determined in TB and HIV, it was recently reported that tasquinimod (a drug that epigenetically reprograms histones and HDAC4 transcription factors) depletes MDSCs, incrementally enhances $\mathrm{CD}^{+} \mathrm{T}$ cell responses, and improves $M$. tuberculosis clearance in mice (99101). The same group also reported that denileukin diftitox treatment reduces $M$. tuberculosis loads in mice, although its safety and MDSC-specificity remain to be demonstrated in humans (102).

Considering the above, technologies based on the detection of proteins or gene expression alone might be inadequate to fully characterize MDSCs. Interventions focused on nongenetic markers may have therapeutic implications. Elucidating epigenetic and posttranslational modifications regulating MDSC induction and function thus remains crucial for both therapeutic development and development of an epigenetic biosignature of TB and HIV disease development and therapy responses.

MDSC-mediated immunosuppression in TB and AIDS. MDSCs suppress $\mathrm{T}$ cell functions considered crucial for host defense to HIV and TB $(7,11-13,88,103)$, but the fields lack comprehensive descriptions of the mechanisms whereby subsets affect pathogen-specific host immunity or which receptors recognize specific pathogen-associated molecular patterns. Instead, a range of suppressive mechanisms have been described, mainly in response to polyclonal stimulation or mitogens $(6,52,79,88,103,104)$.

In $\mathrm{TB}$, MDSC suppressive mechanisms point toward a role for arginase-1 (Arg-1) and NOS2 in repressing T cell proliferation and IFN- $\gamma$ production $(6,55,88,105)$. Depletion of L-arginine by Arg- 1 and NOS 2 downregulates $\mathrm{T}$ cell receptor $\zeta$ chain expression, which impedes $\mathrm{T}$ cell proliferation and aerobic glycolysis, prevents $\mathrm{CD}^{+} \mathrm{T}$ cells from expressing IFN- $\gamma$ and inducing efficient intracellular pathogen killing in macrophages, and blocks formation of immunological synapses, impairing T cell activation $(106,107)$. NO produced by NOS 2 inhibits STAT5 phosphorylation in T cells and induces expansion of CD4 $4^{+}$Tregs (108). MDSCs are known to use NO to suppress lymphocyte proliferation upon both in vitro and aerosol M. tuberculosis infection $(88,109)$. BCG studies further indicate that NO release and suppressor function depend on TLR2/caveolin-1 signals (110). In murine models, Arg-1 expression has been correlated to levels of cells resembling MDSCs in necrotic granulomas $(105,109)$. Studies to establish exclusive requirements of Arg-1 or NOS2 on MDSC suppression in TB patients have been inconclusive, and targeting individual mechanisms may activate "compensatory" suppressive mediators (7).

Information on the contribution of MDSC suppressive pathways previously identified in cancer, including ROS, ADAM17, reactive nitrogen species, TGF- $\beta$, IL-10, L-selectin expression, VISTA, and IDO, should be tested in TB and HIV infection. For example, IL-13 released by NKT cells can activate MSDC for the release of TGF- $\beta$, which is a potent suppressor of $C D 8^{+} \mathrm{T}$ cell immunity (111, 112). Recent reports indicate roles of PD-L1 and transmembrane TNF (tmTNF) in MDSC suppressive activity in TB $(103,113)$. PD-L1 also forms part of the suppressive arsenal of PMN-MDSCs in early HIV infection, along with inhibition of CD3 $\zeta$ expression by cell-tocell contact involving ROS and NOS2 (10-12, 114). M-MDSC suppressive functions in HIV are linked to Arg-1-mediated expansion of Tregs and inhibition of $\mathrm{CD}^{+} \mathrm{T}$ cell proliferation (14). Suppression of M. tuberculosis/HIV-specific T cell responses remains to be tested in patients (7). Moreover, MDSCs suppress other myeloid cells, B cells, NK cells, innate lymphoid cells , and nonclassical T cells, and such effects have not been evaluated in TB or HIV infection.

The diversity of MDSC suppressive mechanisms reported for TB and HIV infection likely reflects multiple redundancies, as reported for cancer. The main suppressive mechanisms may correlate with the dominant MDSC subset, the cellular target, and/or the functional impact, and could change during disease development or in a particular anatomical location (91). Eliminating a single MDSC suppressive mechanism may therefore reduce the levels 
and potency of some but not all MDSCs, or only at distinct disease stages, highlighting the importance of establishing the spatiotemporal dynamics of MDSC subsets, their suppressive functions, and their targets during the TB and HIV infection and disease continua.

Are MDSCs exclusively pathological? Reports on MDSCs are synonymous with deleterious clinical outcomes in cancer $(28,115)$. However, appraisal of MDSCs exclusively as detrimental must be questioned. Although development of disease is, at least in part, a consequence of regulatory cells such as MDSCs, outweighing protective cell responses, the dual nature of MDSCs has also been described. In autoimmunity, and recently in infections, MDSCs' contribution to immune homeostasis by limiting of excessive inflammatory processes has been highlighted (refs. 116-120 and see below). Protection from invading pathogens requires a critical balance between beneficial suppression of damaging excess inflammatory and repair responses and augmentation of effective protective antipathogen responses. In this regard, MDSCs change their fate and activity according to the local microenvironment (121). For example, in SIV infection, MDSCs can suppress $\mathrm{CD} 4^{+} \mathrm{T}$ cell activation and thus reduce target cells for SIV infection, simultaneously inhibiting SIV transmission and promoting it by suppressing immunity (61-63). In pulmonary TB, successful chemotherapy clears $M$. tuberculosis and allows tissue repair, partially through a fibrotic process. A subset of fibrocytes has been described as a novel suppressive MDSC subset in cancer (122), while others have shown in pulmonary fibrosis that M-MDSCs activate resident lung fibroblasts (123). Considering that fibrotic repair often results in tissue scarring that may impair organ function, MDSCs' impact in post-TB lung function remains to be investigated. In HIV-M. tuberculosis coinfection, MDSCs may still increase the risk of TB disease, but in HIV-CMV coinfection these cell subsets control excessive CMV-specific inflammation (15).

Additional investigations are required to identify the kinetics of distinct MDSC subtypes and how their tissue or lesion compartmentalization influences outcomes during different stages of infection. Determining the optimal timing for initiating any HDT will be crucial for successful outcomes to maintain immunoregulatory balance between effective defense and excess damage.

\section{MDSC roles in immunopathology: a case for TB}

Migration/trafficking of MDSCs to lungs in TB. S100A8 and S100A9 are damage-associated molecular patterns (DAMP) proteins produced by myeloid cells, including MDSCs, and secreted into tissues and serum as endogenous danger signals. S100A8 and S100A9 bind to cell surface receptors including receptor for advanced glycation end products (RAGE) and TLR4 $(124,125)$. The S100 proinflammatory protein family promotes MDSC accumulation in cancer (126). In murine and NHP TB models, and TB patients, myeloid cells producing S100A8/A9 proteins dominate within granulomas and are associated with exacerbation of inflammation (127). These S100A8/A9-producing cells have not been tested for suppressive activity. Tasquinimod, a DAMP inhibitor and Treg-targeting drug that binds to S100A9 and blocks surface receptor binding, reduces granuloma formation in a BCG-challenge guinea pig model (128), while S100A9-deficient mice also exhibit reduced inflammation upon $M$. tuberculosis infection (127). Similarly, in a TB mouse model, administration of tasquinimod was associated with a concomitant reduction of MDSCs in the lungs as well as reduced M. tuberculosis replication (99), suggesting a role in reducing MDSC trafficking to the lungs. Many other MDSC chemoattractants have been described, mostly factors produced by tumor cells, like CXCL8 (IL-8) (129), which recruits both PMN- and M-MDSCs (124), whereas only CCR2 ${ }^{+}, \mathrm{CCR} 4^{+}$, and CCR5 ${ }^{+}$M-MDSCs are recruited by its ligands (e.g., CCL2) $(130,131)$, and CXCR2 ${ }^{+} /$CXCR4 ${ }^{+}$PMN-MDSCs by its ligands (e.g., CXCL1, CXCL2, or CXCL12) $(132,133)$. None have been investigated as MDSC chemotactic factors in AIDS or TB.

Fate of MDSCs at TB granulomas? MDSCs populate necrotic areas within granulomas; however, compartmentalization in lung parenchyma and the bronchoalveolar space remains undefined $(88,109)$. In mice, accumulation of MDSCs in necrotic granulomas has been associated with a poor disease outcome and uncontrolled bacterial replication (88). Immunostaining of granulomas from $M$. tuberculosis-infected mice and macaques has identified populations of macrophages coexpressing NOS2 and Arg-1 (134, 135) and suppressive neutrophils exhibiting immunoregulatory functions (136), collectively resembling MDSC subsets. The presence of MDSCs in human TB biopsies has not been documented. However, studies using cellular aggregates for ex vivo modeling of TB granulomas suggest that mycobacterial growth within such multicellular structures can be supported by human MDSCs and has been linked to their propensity to produce IL-10 (103). In murine lesions and human models, MDSCs contain bacteria, raising the question of whether MDSCs could serve as reservoir cells (88). Furthermore, crosstalk between MDSC and bystander cells such as macrophages (137) opens the possibility that MDSCs affect not only polarization of surrounding cells, but also mycobacterial growth dynamics in bystander cells through bidirectional interaction. This will be particularly important in the context of granulomas.

Circulating M- and PMN-MDSCs have a short in vivo lifespan of days, while M-MDSCs are viable in vitro for several days (138). Increased inflammatory signals augment circulating MDSCs, suggesting that inflammation may prolong MDSC half-life (139). Indeed, studies in mice have demonstrated that during oxidative stress, transcription factors involved in enhancing cellular resistance to ROS are upregulated in MDSCs (85), thereby increasing their longevity in the TME (140). These studies also demonstrated homeostatic regulation of MDSC dynamics. A decrease in halflife of tumor-infiltrating MDSCs led to a compensatory increase in MDSC production in the bone marrow and maintenance of MDSC frequencies in the blood (141). Considering the inflammatory milieu of TB and AIDS, similar processes might be involved in MDSC survival, with impact on maintenance of long-lived pathogen reservoirs (141). MDSCs were identified in the bronchoalveolar lavage fluid and pleural effusions of TB patients (7) but were not evaluated for $M$. tuberculosis content. Whether mycobacterial infection modulates MDSC viability and phenotype is also unknown. Several soluble factors present in TB lesions, including prokineticin 2 (PROK2) and the metalloproteinase MMP9, may modulate pulmonary MDSC expansion (88); local accumulation of tmTNF- $\alpha$ has been shown to regulate the dynamics of these cells in the pleural cavity of BCG-infected mice (113). Fate mapping studies are required to define the local turnover and dynamics of MDSCs within granulomas. 
The ultimate fate of MDSCs at the M. tuberculosis infection site or tissue inflammatory environment is uncertain. Several tissue macrophage populations are long-lived and capable of in situ proliferation to sustain $M$. tuberculosis replication $(142,143)$. It is thus tempting to speculate that MDSCs entering the M. tuberculosis-infected lung or granuloma differentiate into suppressive, $M$. tuberculosis growth-permissive macrophages. In cancer, M-MDSCs entering the tumor can differentiate into tumor-promoting, suppressive tumor-associated macrophages (TAMs) or inflammatory DCs, whereas a case is made for PMN-MDSCs differentiating into tumor-associated neutrophils (TANs) (144-146). It is likely that in TB and HIV, a multilevel process of MDSC activation occurs, similar to that reported in vivo and in vitro (79). MDSCs could thus be converted to MDSC-like cells by peripheral signals, and upon entering the inflammatory milieu, host and pathogenic signatures activate these licensed cells to become potent suppressors. Furthermore, while M. tuberculosis can be distributed among alveolar macrophages, DCs, and neutrophils during the initial stages of infection, after prolonged infection, DCs and recruited monocyte-derived macrophages become the prominent infected cell types in the airways (147). MDSCs likely become a prominently infected myeloid subset during the uncontrolled chronic stages of TB disease. MDSC characterization in tissue is challenging yet critical for understanding disease pathogenesis and informing therapy, and can only be achieved by discovery of unique MDSC identifiers with stable expression irrespective of anatomical location.

MDSCs' immunometabolic cues. The metabolic preference of MDSCs is not fully known. It is likely that MDSCs, similarly to other immune cells, may engage distinct metabolic pathways depending on the intermediates available for energy production. The phenotypic heterogeneity of tumor-derived MDSCs is controlled by oxygen levels, fatty acid metabolism, and inflammatory parameters, which may in turn regulate the balance between oxidative phosphorylation (OXPHOS) and glycolysis (148). M- and PMN-MDSCs in the tumor, in comparison with circulating peripheral MDSCs, prefer fatty acid oxidation (FAO) as their energy source (149). MDSCs rely on FAO as the major metabolic fuel for the production of inhibitory cytokines. Consequently, targeting FAO may be a useful approach to limit the immunosuppressive function of MDSCs. Pharmacological inhibition of FAO with etomoxir or ranolazine blocked the immunosuppressive functions of MDSCs in the tumor and significantly delayed tumor growth (149). Interestingly, trimetazidine, an FAO inhibitor used in chronic heart disease, blocks intracellular growth of $M$. tuberculosis (150) and may have advantages also as an MDSC modulator. The immunosuppressive function of PMN-MDSCs in cancer has been linked to overexpression of fatty acid transport protein 2 (FATP2), a lipid transporter, and is reversed upon treatment with lipofermata, causing a significant delay in tumor growth (26).

In contrast, in a mouse tumor model, total MDSCs presented with a significantly increased glycolytic status, whereas only the PMN-MDSC subset used both glycolysis and OXPHOS to produce energy (151). In human tumors, glycolytic signatures that include lactate dehydrogenase A correlated with high MDSC frequencies (152). Others also reported the correlation of glycolysis with
MDSCs in cancer (152), but the plasticity of the myeloid compartment likely explains the switch between glycolysis and OXPHOS, as reported for other myeloid cells in the TME. This is likely also dependent on the stage of cancer development $(153,154)$.

In TB granulomas, metabolic cues, including nutrient and oxygen gradients, lipid-rich macrophages, and enzymatic products such as prostaglandin $\mathrm{E}_{2}$, segregate in distinct zones. Remarkably similarly to solid tumors, granulomas show coordinated upregulation of genes encoding enzymes associated with the Warburg effect, stabilization of the master transcription factor HIF-1 $\alpha$, and accumulation of lactate in infected lung lesions (155). It is thus likely that alterations in MDSC nutrient metabolism and bioenergetic flux in TB and HIV also differ across the diverse and dynamic attributes of the tissue inflammatory milieu and disease stage (156). How these metabolic regulators may affect the course of $M$. tuberculosis and HIV infection, or such metabolic cues modulate MDSC dynamics and function in $\mathrm{TB} / \mathrm{HIV}$, remains to be evaluated. The bioenergetic features of macrophages affect their propensity to support $M$. tuberculosis replication (143), and this remains unknown for MDSCs.

The metabolic profile of myeloid cells, including MDSCs, could also rewire mycobacterial bioenergetic status, and vice versa (157). Energy metabolism in mycobacteria has emerged as a novel target pathway in discovery of new antibacterials (158). An important consideration would thus be the role of MDSCs in the metabolic adaptations of $M$. tuberculosis, notably the impact on mycobacterial growth and dormancy $(159,160)$. Elimination of persisting mycobacterial population is essential for combating latent and active M. tuberculosis infections.

\section{Models to study MDSC biology}

NHP infection with SIV is a widely used model to study MDSCs in HIV and HIV-M. tuberculosis coinfection (elaborated on in MDSCs in vaccination above; refs. $63,111,161,162)$. Preliminary data from this model show that MDSC suppression in SIV occurs through IL-13/TGF- $\beta$ signaling that inhibits T cell proliferation and effector functions. Although studies investigating the benefit of TGF signaling inhibition during antiretroviral therapy are lacking, it is widely accepted that TGF- $\beta$ overproduction is a major cause of both innate and adaptive immune suppression during HIV infection (163). Therefore, calculated blocking TGF- $\beta$ could inhibit tumor growth or synergize with cancer vaccines $(111,164-167)$ and may offer promise in HIV infection.

In the absence of well-characterized, low-maintenance, easyto-handle animal models for HIV, TB, and coinfection, ex vivo models serve as good alternatives for studying MDSCs. Using PBMCs, such a coculture model was developed from HIV-uninfected TB patients (7), and also adapted to model HIV-uninfected and -infected individuals with more than $200 \mathrm{CD}^{+} \mathrm{T}$ cells, to demonstrate the expansion and suppressive function of MDSCs $(11,15,168)$. Such models have demonstrated increased circulating M-MDSC frequencies in comparison with healthy controls (12, 15). The limitation of using cryopreserved PBMCs is that mononuclear cells are enriched at the expense of granulocytes and can skew findings (13). In HIV-TB coinfection, results suggest that comparable surface expression of TLR2 and TLR4 on HLA-DR ${ }^{\text {hi }}$ and M-MDSC subsets exists in HIV-infected individuals with viral suppression, but demonstrate defective signaling in response to 
M. tuberculosis antigens through lower quantities of IL-12 p70 and TNF- $\alpha$ production (169). These recapitulate observed cytokine outcomes in HIV-M. tuberculosis-coinfected individuals, suggesting the reliability of the ex vivo system. The elevated numbers of MDSCs measured within lung and bone marrow in mouse models of pulmonary TB $(88,170)$ correspond to findings in patients $(7$, 169), thus highlighting the appropriate use of both clinical and animal models to understand the role of MDSCs in TB. Nonetheless, considering the discreet variability in MDSC functions amongst subsets and anatomical site, and in TB and HIV, the requirement for large-scale and standardized ex vivo production of functional MDSC for studies has been suggested.

\section{Future prospects, conclusions, and recommendations}

Although important contributions and efforts have been undertaken to understand MDSCs in TB and AIDS, incomplete knowledge about their differentiation, functions, and mechanisms delays clinical utilization of MDSC-based therapeutics. Topics highlighted as key research priorities in TB and AIDS include (a) the role of MDSCs in TB granulomas; (b) establishing a beneficial balance between MDSC-mediated inflammatory suppression/healing and augmentation of effective immunity; (c) determining the abundances and functions of MDSC subsets at various anatomical locations across infection stages to guide choices and timing of targeted interventions; (d) the role of MDSCs as a pathogen reservoir; (e) delineating interactions with other immune cells and mechanisms (miRNAs, exosomes, etc.); (f) knowledge regarding epigenetic changes regulating MDSCs; (g) the use of MDSCs as biomarkers; (h) evaluating MDSC-directed therapeutic approaches; and (i) exploring the manipulation of MDSCs to potentiate vaccine outcomes. Considering the common pathophysiological mechanisms and perturbations in immune pathways and functions shared by cancer and infection, evaluating MDSC discoveries and interventions from oncology in TB and AIDS should take precedence. Fundamental advancement of MDSC research in infections requires development of an MDSC program, whereby TB and HIV researchers coordinate research priorities and strategies with those in the cancer field. Such synergy and cross-fertilization among disciplines and sectors will be critical to unlocking the clinical potential and therapeutic translation of MDSC research findings from bench to bedside.

\section{Acknowledgments}

The authors thank Helga Keßler for editorial assistance, Michael R. Knittler for assistance with the graphics work, and our fellow workshop presenters, Evgeniy Eruslanov, Anne Goldfeld, Tim Greten, Tom Ottenhoff, and Ethan Shevach, for their insights and lively discussion. This work has been supported by the Division of AIDS, National Institute of Allergy and Infectious Diseases, NIH, Department of Health and Human Services (contract HHSN272201600001G-Research Support Services for the Division of AIDS support for this publication and the workshop Suppressor Cells and TB/HIV: What Is Known and What Can Be Learned?, January 2019). WB gratefully acknowledges the support of NIH grants AI37856, HL133190, and AI130595. AG is funded by NIH AI127132 and the University of Georgia Research Foundation. NDP is sponsored by the European and Developing Countries Clinical Trials Partnership (CDF1546).

Address correspondence to: Anca Dorhoi, Südufer 10, 17493 Greifswald-Insel Riems, Germany. Phone: 49.38351.7.1624; Email: anca.dorhoi@fli.de. Or to: Nelita du Plessis, Division of Molecular Biology and Human Genetics, Department of Biomedical Sciences, Faculty of Medicine and Health Sciences, Stellenbosch University, FISAN Building, Room F312, Tygerberg 7505, South Africa. Phone: 27.21.938.9953; Email: nelita@sun.ac.za.
1. Young MR, Young ME, Wright MA. Myelopoiesisassociated suppressor-cell activity in mice with Lewis lung carcinoma tumors: interferon- $\gamma$ plus tumor necrosis factor- $\alpha$ synergistically reduce suppressor cell activity. Int J Cancer. 1990;46(2):245-250.

2. Young MR, Wright MA, Lozano Y, Matthews JP, Benefield J, Prechel MM. Mechanisms of immune suppression in patients with head and neck cancer: influence on the immune infiltrate of the cancer. Int J Cancer. 1996;67(3):333-338.

3. Gabrilovich DI, et al. The terminology issue for myeloid-derived suppressor cells. Cancer Res. 2007;67(1):425; author reply 426.

4. Bronte V, et al. Recommendations for myeloidderived suppressor cell nomenclature and characterization standards. Nat Commun. 2016;7:12150.

5. Bennett JA, Rao VS, Mitchell MS. Systemic bacillus Calmette-Guérin (BCG) activates natural suppressor cells. Proc Natl Acad Sci U S A. 1978;75(10):5142-5144.

6. El Daker S, et al. Granulocytic myeloid derived suppressor cells expansion during active pulmonary tuberculosis is associated with high nitric oxide plasma level. PLoS One. 2015;10(4):e0123772.

7. du Plessis N, et al. Increased frequency of myeloid-derived suppressor cells during active tuberculosis and after recent mycobacterium tuberculosis infection suppresses T-cell function. Am J Respir Crit Care Med. 2013;188(6):724-732.

8. Tumino N, et al. In HIV-positive patients, myeloid-derived suppressor cells induce T-cell anergy by suppressing CD3 expression through ELF-1 inhibition. AIDS. 2015;29(18):2397-2407.

9. Ostrand-Rosenberg S, Sinha P. Myeloid-derived suppressor cells: linking inflammation and cancer. JImmunol. 2009;182(8):4499-4506.

10. Tumino N, et al. Granulocytic myeloid-derived suppressor cells increased in early phases of primary HIV infection depending on TRAIL plasma level. JAcquir Immune Defic Syndr. 2017;74(5):575-582.

11. Garg A, Spector SA. HIV type 1 gp120-induced expansion of myeloid derived suppressor cells is dependent on interleukin 6 and suppresses immunity. J Infect Dis. 2014;209(3):441-451.

12. Qin A, et al. Expansion of monocytic myeloidderived suppressor cells dampens T cell function in HIV-1-seropositive individuals. J Virol. 2013;87(3):1477-1490.

13. Vollbrecht T, et al. Chronic progressive HIV-1 infection is associated with elevated levels of myeloid-derived suppressor cells. AIDS. 2012;26(12):F31-F37.
14. Wang L, et al. Expansion of myeloid-derived suppressor cells promotes differentiation of regulatory T cells in HIV-1+ individuals. AIDS 2016;30(10):1521-1531.

15. Garg A, Trout R, Spector SA. Human immunodeficiency virus type-1 myeloid derived suppressor cells inhibit cytomegalovirus inflammation through interleukin-27 and B7-H4. Sci Rep. 2017;7:44485.

16. Fleming V, et al. Targeting myeloid-derived suppressor cells to bypass tumor-induced immunosuppression. Front Immunol. 2018;9:398.

17. du Plessis N, Kotze LA, Leukes V, Walzl G. Translational potential of therapeutics targeting regulatory myeloid cells in tuberculosis. Front Cell Infect Microbiol. 2018;8:332.

18. Movahedi K, et al. Identification of discrete tumor-induced myeloid-derived suppressor cell subpopulations with distinct T cell-suppressive activity. Blood. 2008;111(8):4233-4244.

19. Youn JI, Nagaraj S, Collazo M, Gabrilovich DI. Subsets of myeloid-derived suppressor cells in tumor-bearing mice. JImmunol. 2008;181(8):5791-5802.

20. Goldmann O, Beineke A, Medina E. Identification of a novel subset of myeloid-derived suppressor cells during chronic staphylococcal infection that resembles immature eosinophils. 
J Infect Dis. 2017;216(11):1444-1451.

21. Dorhoi A, Du Plessis N. Monocytic myeloidderived suppressor cells in chronic infections. Front Immunol. 2017;8:1895.

22. Mandruzzato S, et al. Toward harmonized phenotyping of human myeloid-derived suppressor cells by flow cytometry: results from an interim study. Cancer Immunol Immunother. 2016;65(2):161-169.

23. Zhao F, et al. S100A9 a new marker for monocytic human myeloid-derived suppressor cells. Immunology. 2012;136(2):176-183.

24. Condamine T, et al. Lectin-type oxidized LDL receptor-1 distinguishes population of human polymorphonuclear myeloid-derived suppressor cells in cancer patients. Sci Immunol. 2016;1(2):aaf8943.

25. Chai E, Zhang L, Li C. LOX-1+ PMN-MDSC enhances immune suppression which promotes glioblastoma multiforme progression. Cancer Manag Res. 2019;11:7307-7315.

26. Veglia F, et al. Fatty acid transport protein 2 reprograms neutrophils in cancer. Nature. 2019;569(7754):73-78.

27. Solito S, Marigo I, Pinton L, Damuzzo V, Mandruzzato S, Bronte V. Myeloid-derived suppressor cell heterogeneity in human cancers. Ann N Y Acad Sci. 2014;1319:47-65.

28. Lang S, et al. Clinical relevance and suppressive capacity of human myeloid-derived suppressor cell subsets. Clin Cancer Res. 2018;24(19):4834-4844.

29. Najjar YG, et al. Accumulation of MDSC subsets in renal cell carcinoma correlates with grade and progression free survival, and is associated with intratumoral expression of IL-1 $1 \beta$, IL-8 and CXCL5. JImmunother Cancer. 2014;2(suppl 3):P227.

30. Finke J, Ko J, Rini B, Rayman P, Ireland J, Cohen P. MDSC as a mechanism of tumor escape from sunitinib mediated anti-angiogenic therapy. Int Immunopharmacol. 2011;11(7):856-861.

31. Najjar YG, et al. Myeloid-derived suppressor cell subset accumulation in renal cell carcinoma parenchyma is associated with intratumoral expression of IL1 $\beta$, IL8, CXCL5, and Mip-1 $\alpha$. Clin Cancer Res. 2017;23(9):2346-2355.

32. Delaunay M, et al. Baseline circulating myeloid-derived suppressor cells and response to PD-1 inhibitor in non-small cell lung cancer patients. JClin Oncol. 2018;36(5_suppl):145.

33. Idorn M, Køllgaard T, Kongsted P, Sengeløv L, Thor Straten P. Correlation between frequencies of blood monocytic myeloid-derived suppressor cells, regulatory $\mathrm{T}$ cells and negative prognostic markers in patients with castration-resistant metastatic prostate cancer. Cancer Immunol Immunother. 2014;63(11):1177-1187.

34. Dominguez GA, et al. Selective targeting of myeloid-derived suppressor cells in cancer patients using DS-8273a, an agonistic TRAIL-R2 antibody. Clin Cancer Res. 2017;23(12):2942-2950.

35. Dolcetti L, et al. Hierarchy of immunosuppressive strength among myeloid-derived suppressor cell subsets is determined by GM-CSF. Eur J Immunol. 2010;40(1):22-35.

36. Diaz-Montero CM, Salem ML, Nishimura MI, Garrett-Mayer E, Cole DJ, Montero AJ. Increased circulating myeloid-derived suppressor cells correlate with clinical cancer stage, metastatic tumor burden, and doxorubicin-cyclophosphamide chemotherapy Cancer Immunol Immunother. 2009;58(1):49-59.

37. Ai L, et al. Prognostic role of myeloid-derived suppressor cells in cancers: a systematic review and meta-analysis. BMC Cancer. 2018;18(1):1220.

38. Greenhill C. Thyroid cancer: use of MDSC to assess malignancy. Nat Rev Endocrinol. 2016;12(3):125.

39. Gnjatic $S$, et al. Identifying baseline immunerelated biomarkers to predict clinical outcome of immunotherapy. JImmunother Cancer. 2017;5:44.

40. Angell TE, et al. Circulating myeloid-derived suppressor cells predict differentiated thyroid cancer diagnosis and extent. Thyroid. 2016;26(3):381-389.

41. Sade-Feldman M, et al. Clinical significance of circulating $\mathrm{CD}^{2} 3^{+} \mathrm{CD} 11 \mathrm{~b}^{+} \mathrm{HLA}-\mathrm{DR}^{-}$myeloid cells in patients with stage IV melanoma treated with ipilimumab. Clin Cancer Res. 2016;22(23):5661-5672.

42. Weide B, et al. Myeloid-derived suppressor cells predict survival of patients with advanced melanoma: comparison with regulatory $\mathrm{T}$ cells and NY-ESO-1- or melan-A-specific T cells. Clin Cancer Res. 2014;20(6):1601-1609.

43. Mayer-Barber KD, et al. Innate and adaptive interferons suppress IL-1 $\alpha$ and IL- $1 \beta$ production by distinct pulmonary myeloid subsets during Mycobacterium tuberculosis infection. Immunity. 2011;35(6):1023-1034.

44. Biswas SK, Mantovani A. Macrophage plasticity and interaction with lymphocyte subsets: cancer as a paradigm. Nat Immunol.2010;11(10):889-896.

45. Almeida FM, et al. Hypervirulent Mycobacterium tuberculosis strain triggers necrotic lung pathology associated with enhanced recruitment of neutrophils in resistant C57BL/6 mice. PLoS One. 2017;12(3):e0173715.

46. Ding AS, Routkevitch D, Jackson C, Lim M. Targeting myeloid cells in combination treatments for glioma and other tumors. Front Immunol. 2019;10:1715.

47. Eriksson E, Wenthe J, Irenaeus S, Loskog A, Ullenhag G. Gemcitabine reduces MDSCs, tregs and TGF $\beta$ - 1 while restoring the teff/treg ratio in patients with pancreatic cancer.J Transl Med. 2016;14(1):282.

48. Santegoets SJ, et al. Myeloid derived suppressor and dendritic cell subsets are related to clinical outcome in prostate cancer patients treated with prostate GVAX and ipilimumab. JImmunother Cancer. 2014;2:31.

49. Andersen P, Doherty TM. The success and failure of BCG - implications for a novel tuberculosis vaccine. Nat Rev Microbiol. 2005;3(8):656-662.

50. Schaible UE, Linnemann L, Redinger N, Patin EC, Dallenga T. Strategies to improve vaccine efficacy against tuberculosis by targeting innate immunity. Front Immunol. 2017;8:1755.

51. Kaufmann SH, Weiner J, von Reyn CF. Novel approaches to tuberculosis vaccine development. Int J Infect Dis. 2017;56:263-267.

52. Martino A, et al. Mycobacterium bovis bacillus Calmette-Guérin vaccination mobilizes innate myeloid-derived suppressor cells restraining in vivo T cell priming via IL-1R-dependent nitric oxide production. JImmunol.2010;184(4):2038-2047.

53. Billiau A, Matthys P. Modes of action of Freund's adjuvants in experimental models of autoimmune diseases. JLeukoc Biol. 2001;70(6):849-860.

54. Coffman RL, Sher A, Seder RA. Vaccine adjuvants: putting innate immunity to work. Immunity. 2010;33(4):492-503.

55. Ribechini E, et al. Heat-killed Mycobacterium tuberculosis prime-boost vaccination induces myeloid-derived suppressor cells with spleen dendritic cell-killing capability. JCI Insight. 2019;4(13):e128664.

56. Jayashankar L, Hafner R. Adjunct strategies for tuberculosis vaccines: modulating key immune cell regulatory mechanisms to potentiate vaccination. Front Immunol. 2016;7:577.

57. Boer MC, Joosten SA, Ottenhoff TH. Regulatory T-cells at the interface between human host and pathogens in infectious diseases and vaccination. Front Immunol. 2015;6:217.

58. Ndure J, Flanagan KL. Targeting regulatory $\mathrm{T}$ cells to improve vaccine immunogenicity in early life. Front Microbiol. 2014;5:477.

59. He YM, et al. Transitory presence of myeloid-derived suppressor cells in neonates is critical for control of inflammation. Nat Med.2018;24(2):224-231

60. de Bree LCJ, et al. Non-specific effects of vaccines: current evidence and potential implications. Semin Immunol. 2018;39:35-43.

61. Sui Y, et al. Vaccine-induced myeloid cell population dampens protective immunity to SIV. JClin Invest. 2014;124(6):2538-2549.

62. Sui $Y$, et al. Mucosal vaccine efficacy against intrarectal SHIV is independent of anti-Env antibody response. JClin Invest. 2019;129(3):1314-1328.

63. Sui Y, et al. Paradoxical myeloid-derived suppressor cell reduction in the bone marrow of SIV chronically infected macaques. PLoS Pathog. 2017;13(5):e1006395

64. Suzuki E, Kapoor V, Jassar AS, Kaiser LR, Albelda SM. Gemcitabine selectively eliminates splenic $\mathrm{Gr}-1+/ \mathrm{CD} 11 \mathrm{~b}+$ myeloid suppressor cells in tumor-bearing animals and enhances antitumor immune activity. Clin Cancer Res. 2005;11(18):6713-6721.

65. Sinha P, Clements VK, Bunt SK, Albelda SM, Ostrand-Rosenberg S. Cross-talk between myeloid-derived suppressor cells and macrophages subverts tumor immunity toward a type 2 response. JImmunol. 2007;179(2):977-983.

66. Vincent J, et al. 5-Fluorouracil selectively kills tumor-associated myeloid-derived suppressor cells resulting in enhanced T cell-dependent antitumor immunity. Cancer Res. 2010;70(8):3052-3061.

67. Apetoh L, Végran F, Ladoire S, Ghiringhelli F. Restoration of antitumor immunity through selective inhibition of myeloid derived suppressor cells by anticancer therapies. Curr Mol Med. 2011;11(5):365-372.

68. Tebartz C, et al. A major role for myeloid-derived suppressor cells and a minor role for regulatory $\mathrm{T}$ cells in immunosuppression during Staphylococcus aureus infection. J Immunol. 2015;194(3):1100-1111.

69. Bruchard M, et al. Chemotherapy-triggered cathepsin B release in myeloid-derived suppressor cells activates the Nlrp3 inflammasome and promotes tumor growth. Nat Med. 2013;19(1):57-64.

70. Morales JK, et al. Myeloid-derived suppressor cells enhance IgE-mediated mast cell responses. JLeukoc Biol. 2014;95(4):643-650.

71. Zhang Y, Bush X, Yan B, Chen JA. Gemcitabine nanoparticles promote antitumor immunity 
against melanoma. Biomaterials. 2019;189:48-59.

72. Najjar YG, Finke JH. Clinical perspectives on targeting of myeloid derived suppressor cells in the treatment of cancer. Front Oncol. 2013;3:49.

73. Draghiciu O, Lubbers J, Nijman HW, Daemen T. Myeloid derived suppressor cells-An overview of combat strategies to increase immunotherapy efficacy. Oncoimmunology. 2015;4(1):e954829.

74. Heine A, et al. The induction of human myeloid derived suppressor cells through hepatic stellate cells is dose-dependently inhibited by the tyrosine kinase inhibitors nilotinib, dasatinib and sorafenib, but not sunitinib. Cancer Immunol Immunother. 2016;65(3):273-282.

75. Yu B, et al. Effective combination of chemotherapy and dendritic cell administration for the treatment of advanced-stage experimental breast cancer. Clin Cancer Res. 2003;9(1):285-294.

76. Kodumudi KN, Woan K, Gilvary DL, Sahakian E, Wei S, Djeu JY. A novel chemoimmunomodulating property of docetaxel: suppression of myeloid-derived suppressor cells in tumor bearers. Clin Cancer Res. 2010;16(18):4583-4594.

77. Welters MJ, et al. Vaccination during myeloid cell depletion by cancer chemotherapy fosters robust T cell responses. Sci Transl Med. 2016;8(334):334ra52.

78. Beyranvand Nejad E, et al. Tumor eradication by cisplatin is sustained by CD80/86-mediated costimulation of $\mathrm{CD}^{+} \mathrm{T}$ cells. Cancer Res. 2016;76(20):6017-6029.

79. Ribechini E, et al. Novel GM-CSF signals via IFN- $\gamma$ R/IRF- 1 and AKT/mTOR license monocytes for suppressor function. Blood $A d v$. 2017;1(14):947-960.

80. Hanoteau A, et al. Tumor microenvironment modulation enhances immunologic benefit of chemoradiotherapy. Jimmunother Cancer. 2019;7(1):10.

81. Kusmartsev S, et al. All-trans-retinoic acid eliminates immature myeloid cells from tumor-bearing mice and improves the effect of vaccination. Cancer Res. 2003;63(15):4441-4449.

82. Mirza N, et al. All-trans-retinoic acid improves differentiation of myeloid cells and immune response in cancer patients. Cancer Res. 2006;66(18):9299-9307.

83. Kusmartsev S, et al. Reversal of myeloid cell-mediated immunosuppression in patients with metastatic renal cell carcinoma. Clin Cancer Res. 2008;14(24):8270-8278.

84. Nefedova Y, Fishman M, Sherman S, Wang X, Beg AA, Gabrilovich DI. Mechanism of alltrans retinoic acid effect on tumor-associated myeloid-derived suppressor cells. Cancer Res. 2007;67(22):11021-11028.

85. Ohl K, Tenbrock K. Reactive oxygen species as regulators of MDSC-mediated immune suppression. Front Immunol. 2018;9:2499.

86. Vasquez-Dunddel D, et al. STAT3 regulates arginase-I in myeloid-derived suppressor cells from cancer patients. J Clin Invest. 2013;123(4):1580-1589.

87. Mourik BC, et al. Immunotherapy added to antibiotic treatment reduces relapse of disease in a mouse model of tuberculosis. Am J Respir Cell Mol Biol. 2017;56(2):233-241.

88. Knaul JK, et al. Lung-residing myeloid-derived suppressors display dual functionality in murine pulmonary tuberculosis. Am J Respir Crit Care Med. 2014;190(9):1053-1066.

89. Wang Z, Jiang J, Li Z, Zhang J, Wang H, Qin Z. A myeloid cell population induced by Freund adjuvant suppresses T-cell-mediated antitumor immunity. J Immunother. 2010;33(2):167-177.

90. Ost M, Singh A, Peschel A, Mehling R, Rieber N, Hartl D. Myeloid-derived suppressor cells in bacterial infections. Front Cell Infect Microbiol. 2016;6:37.

91. Gabrilovich DI, Nagaraj S. Myeloid-derived suppressor cells as regulators of the immune system. Nat Rev Immunol. 2009;9(3):162-174.

92. Millrud CR, Bergenfelz C, Leandersson K. On the origin of myeloid-derived suppressor cells. Oncotarget. 2017;8(2):3649-3665.

93. Sahakian E, et al. Histone deacetylase 11: a novel epigenetic regulator of myeloid derived suppressor cell expansion and function. Mol Immunol. 2015;63(2):579-585.

94. Youn J-I, Lee K, Lee H-C, Gabrilovich DI. Loss of $\mathrm{Rb} 1$ by epigenetic modification regulates expansion of MDSC in cancer. J Immunother Cancer. 2014;2(suppl 3):P241.

95. Man L, Zhou J, Wong J, Chan AWH, Chen Z, Cheng ASL. Delineating the epigenetic regulation of myeloid derived suppressor cell generation in hepatocellular carcinoma associated with cirrhosis. J Immunol. 2017;198(1 suppl):205.

96. Gao Y, et al. $L n c-C / E B P \beta$ modulates differentiation of MDSCs through downregulating IL4i1 With C/EBP $\beta$ LIP and WDR5. Front Immunol. 2019;10:1661.

97. Sido JM, Yang X, Nagarkatti PS, Nagarkatti M. $\Delta$ 9-Tetrahydrocannabinol-mediated epigenetic modifications elicit myeloid-derived suppressor cell activation via STAT3/S100A8. J Leukoc Biol. 2015;97(4):677-688.

98. Youn JI, et al. Epigenetic silencing of retinoblastoma gene regulates pathologic differentiation of myeloid cells in cancer. Nat Immunol. 2013;14(3):211-220.

99. Gupta S, et al. Pharmacologic exhaustion of suppressor cells with tasquinimod enhances bacterial clearance during tuberculosis. Am J Respir Crit Care Med. 2019;199(3):386-389.

100.Gupta N, Al Ustwani O, Shen L, Pili R. Mechanism of action and clinical activity of tasquinimod in castrate-resistant prostate cancer. Onco Targets Ther. 2014;7:223-234.

101. Isaacs JT, et al. Tasquinimod is an allosteric modulator of HDAC4 survival signaling within the compromised cancer microenvironment. Cancer Res. 2013;73(4):1386-1399.

102. Gupta S, et al. Suppressor cell-depleting immunotherapy with denileukin diftitox is an effective host-directed therapy for tuberculosis. J Infect Dis. 2017;215(12):1883-1887.

103. Agrawal N, et al. Human monocytic suppressive cells promote replication of Mycobacterium tuberculosis and alter stability of in vitro generated granulomas. Front Immunol. 2018;9:2417.

104. Garg A, Spector SA. HIV myeloid derived suppressor cells (MDSC) are defective in innate immunity to Mycobacterium bovis BCG. JImmunol. 2017;198(1 suppl):68

105. Domingo-Gonzalez R, et al. Interleukin-17 limits hypoxia-inducible factor $1 \alpha$ and development of hypoxic granulomas during tuberculosis. JCI Insight. 2017;2(19):92973.

106. Rodriguez PC, Ochoa AC, Al-Khami AA. Arginine metabolism in myeloid cells shapes innate and adaptive immunity. Front Immunol. 2017;8:93.

107. Rodriguez PC, Quiceno DG, Ochoa AC. L-arginine availability regulates T-lymphocyte cell-cycle progression. Blood. 2007;109(4):1568-1573.

108. Niedbala W, Cai B, Liew FY. Role of nitric oxide in the regulation of T cell functions. Ann Rheum Dis. 2006;65(suppl 3):iii37-iii40.

109. Obregón-Henao A, Henao-Tamayo M, Orme IM, Ordway DJ. Gr1(int)CD11b ${ }^{+}$myeloid-derived suppressor cells in Mycobacterium tuberculosis infection. PLoS One. 2013;8(11):e80669.

110. John V, Kotze LA, Ribechini E, Walzl G, Du Plessis N, Lutz MB. Caveolin-1 controls vesicular TLR2 expression, $\mathrm{p} 38$ signaling and $\mathrm{T}$ cell suppression in BCG infected murine monocytic myeloid-derived suppressor cells. Front Immunol. 2019;10:2826.

111. Terabe M, et al. Transforming growth factor-beta production and myeloid cells are an effector mechanism through which CD1d-restricted T cells block cytotoxic T lymphocyte-mediated tumor immunosurveillance: abrogation prevents tumor recurrence. J Exp Med. 2003;198(11):1741-1752.

112. Fichtner-Feigl S, et al. Restoration of tumor immunosurveillance via targeting of interleukin-13 receptor- $\alpha 2$. Cancer Res. 2008;68(9):3467-3475.

113. Chavez-Galan L, et al. Transmembrane tumor necrosis factor controls myeloid-derived suppressor cell activity via tnf receptor 2 and protects from excessive inflammation during BCG-induced pleurisy. Front Immunol. 2017;8:999.

114. Zhang ZN, et al. Myeloid-derived suppressor cells associated with disease progression in primary HIV infection: PD-L1 blockade attenuates inhibition. J Acquir Immune Defic Syndr. 2017;76(2):200-208.

115. Okła K, et al. Clinical relevance and immunosuppressive pattern of circulating and infiltrating subsets of myeloid-derived suppressor cells (MDSCs) in epithelial ovarian cancer. Front Immunol. 2019;10:691.

116. Schmid M, Zimara N, Wege AK, Ritter U. Myeloid-derived suppressor cell functionality and interaction with Leishmania major parasites differ in C57BL/6 and BALB/c mice. Eur J Immunol. 2014;44(11):3295-3306.

117. Cuervo H, et al. Myeloid-derived suppressor cells infiltrate the heart in acute Trypanosoma cruzi infection. J Immunol. 2011;187(5):2656-2665.

118. Rieber N, et al. Flagellin induces myeloid-derived suppressor cells: implications for Pseudomonas aeruginosa infection in cystic fibrosis lung disease. JImmunol. 2013;190(3):1276-1284.

119. Poe SL, et al. STAT1-regulated lung MDSC-like cells produce IL-10 and efferocytose apoptotic neutrophils with relevance in resolution of bacterial pneumonia. Mucosal Immunol. 2013;6(1):189-199.

120. Peñaloza HF, et al. Interleukin-10 produced by myeloid-derived suppressor cells provides protection to carbapenem-resistant Klebsiella pneumoniae sequence type 258 by enhancing its clearance in the airways. Infect Immun. 2019;87(5):e00665-18 
121. Corzo CA, et al. HIF- $1 \alpha$ regulates function and differentiation of myeloid-derived suppressor cells in the tumor microenvironment. JExp Med. 2010;207(11):2439-2453.

122.Zhang $\mathrm{H}$, et al. Fibrocytes represent a novel MDSC subset circulating in patients with metastatic cancer. Blood. 2013;122(7):1105-1113.

123. Liu T, Rinke A, Flaherty K, Phan SH. Potential role of myeloid-derived suppressor cells in pulmonary fibrosis. J Immunol. 2019;202(1 suppl):182.

124. Srikrishna G. S100A8 and S100A9: new insights into their roles in malignancy. JInnate Immun. 2012;4(1):31-40.

125. Srikrishna G, Freeze HH. Endogenous damage-associated molecular pattern molecules at the crossroads of inflammation and cancer. Neoplasia. 2009;11(7):615-628.

126. Sinha P, Okoro C, Foell D, Freeze HH, Ostrand-Rosenberg S, Srikrishna G. Proinflammatory $\mathrm{S} 100$ proteins regulate the accumulation of myeloid-derived suppressor cells. J Immunol. 2008;181(7):4666-4675.

127. Gopal R, et al. S100A8/A9 proteins mediate neutrophilic inflammation and lung pathology during tuberculosis. Am J Respir Crit Care Med. 2013;188(9):1137-1146

128. Yoshioka Y, et al. Neutrophils and the S100A9 protein critically regulate granuloma formation. Blood Adv. 2016;1(3):184-192.

129. Alfaro C, et al. Tumor-produced interleukin-8 attracts human myeloid-derived suppressor cells and elicits extrusion of neutrophil extracellular traps (NETs). Clin Cancer Res. 2016;22(15):3924-3936.

130. Lesokhin AM, et al. Monocytic CCR2(+) myeloid-derived suppressor cells promote immune escape by limiting activated CD8 T-cell infiltration into the tumor microenvironment. Cancer Res. 2012;72(4):876-886.

131. Zhang J, Patel L, Pienta KJ. CC chemokine ligand 2 (CCL2) promotes prostate cancer tumorigenesis and metastasis. Cytokine Growth Factor Rev. 2010;21(1):41-48.

132. Kang X, et al. CXCR2-mediated granulocytic myeloid-derived suppressor cells' functional characterization and their role in maternal fetal interface. DNA Cell Biol. 2016;35(7):358-365.

133. Benedicto A, Romayor I, Arteta B. CXCR4 receptor blockage reduces the contribution of tumor and stromal cells to the metastatic growth in the liver. Oncol Rep. 2018;39(4):2022-2030.

134. Mattila JT, et al. Microenvironments in tuberculous granulomas are delineated by distinct populations of macrophage subsets and expression of nitric oxide synthase and arginase isoforms. J Immunol. 2013;191(2):773-784.

135. Duque-Correa MA, et al. Macrophage arginase-1 controls bacterial growth and pathology in hypoxic tuberculosis granulomas. Proc Natl Acad Sci U S A. 2014;111(38):E4024-E4032.

136. Gideon HP, Phuah J, Junecko BA, Mattila JT. Neutrophils express pro- and anti-inflammatory cytokines in granulomas from Mycobacterium tuberculosis-infected cynomolgus macaques. Mucosal Immunol. 2019;12(6):1370-1381.

137. Beury DW, Parker KH, Nyandjo M, Sinha P, Carter KA, Ostrand-Rosenberg S. Cross-talk among myeloid-derived suppressor cells, macrophages, and tumor cells impacts the inflammatory milieu of solid tumors. JLeukoc Biol. 2014;96(6):1109-1118. 138. Ostrand-Rosenberg S, Fenselau C. Myeloidderived suppressor cells: immune-suppressive cells that impair antitumor immunity and are sculpted by their environment. JImmunol. 2018;200(2):422-431.

139. Bunt SK, Yang L, Sinha P, Clements VK, Leips J, Ostrand-Rosenberg S. Reduced inflammation in the tumor microenvironment delays the accumulation of myeloid-derived suppressor cells and limits tumor progression. Cancer Res. 2007;67(20):10019-10026.

140. Parker KH, Beury DW, Ostrand-Rosenberg S. Myeloid-derived suppressor cells: critical cells driving immune suppression in the tumor microenvironment. Adv Cancer Res. 2015;128:95-139.

141. Beury DW, et al. Myeloid-derived suppressor cell survival and function are regulated by the transcription factor Nrf2. J Immunol. 2016;196(8):3470-3478.

142. Gibbings SL, et al. Three unique interstitial macrophages in the murine lung at steady state. $A m J$ Respir Cell Mol Biol. 2017;57(1):66-76.

143. Huang L, Nazarova EV, Tan S, Liu Y, Russell DG. Growth of Mycobacterium tuberculosis in vivo segregates with host macrophage metabolism and ontogeny. J Exp Med. 2018;215(4):1135-1152.

144.Veglia F, Perego M, Gabrilovich D. Myeloid-derived suppressor cells coming of age. Nat Immunol. 2018;19(2):108-119.

145. Ugel S, De Sanctis F, Mandruzzato S, Bronte V. Tumor-induced myeloid deviation: when myeloid-derived suppressor cells meet tumor-associated macrophages. JClin Invest. 2015;125(9):3365-3376.

146.Tesi RJ. MDSC; the most important cell you have never heard of. Trends Pharmacol Sci. 2019;40(1):4-7.

147. Cohen SB, et al. Alveolar macrophages provide an early Mycobacterium tuberculosis niche and initiate dissemination. Cell Host Microbe. 2018;24(3):439-446.e4.

148. Groth C, et al. Immunosuppression mediated by myeloid-derived suppressor cells (MDSCs) during tumour progression. Br J Cancer. 2019;120(1):16-25.

149. Hossain F, et al. Inhibition of fatty acid oxidation modulates immunosuppressive functions of myeloid-derived suppressor cells and enhances cancer therapies. Cancer Immunol Res. 2015;3(11):1236-1247.

150. Chandra P, et al. Fatty acid oxidation impairs macrophage effector functions that control Mycobacterium tuberculosis [preprint]. https:// doi.org/10.1101/799619. Posted on bioRxiv October 10, 2019.

151. Jian SL, et al. Glycolysis regulates the expansion of myeloid-derived suppressor cells in tumor-bearing hosts through prevention of ROS-mediated apoptosis. Cell Death Dis. 2017;8(5):e2779.

152. Li W, et al. Aerobic glycolysis controls myeloidderived suppressor cells and tumor immunity via a specific CEBPB isoform in triple-negative breast cancer. Cell Metab. 2018;28(1):87-103.e6.

153. Blagih J, Jones RG. Polarizing macrophages through reprogramming of glucose metabolism. Cell Metab. 2012;15(6):793-795.
154. Yang WC, Ma G, Chen SH, Pan PY. Polarization and reprogramming of myeloid-derived suppressor cells. J Mol Cell Biol. 2013;5(3):207-209.

155. Shi L, Salamon H, Eugenin EA, Pine R, Cooper A, Gennaro ML. Infection with Mycobacterium tuberculosis induces the Warburg effect in mouse lungs. Sci Rep. 2015;5:18176.

156. Biswas SK. Metabolic reprogramming of immune cells in cancer progression. Immunity. 2015;43(3):435-449.

157. Cumming BM, Addicott KW, Adamson JH, Steyn AJ. Mycobacterium tuberculosis induces decelerated bioenergetic metabolism in human macrophages. Elife. 2018;7:e39169.

158. Bald D, Villellas C, Lu P, Koul A. Targeting energy metabolism in Mycobacterium tuberculosis, a new paradigm in antimycobacterial drug discovery. mBio. 2017;8(2):e00272-17.

159. Wayne LG. Dormancy of Mycobacterium tuberculosis and latency of disease. Eur J Clin Microbiol Infect Dis. 1994;13(11):908-914.

160.Lee W, VanderVen BC, Fahey RJ, Russell DG. Intracellular Mycobacterium tuberculosis exploits host-derived fatty acids to limit metabolic stress. J Biol Chem. 2013;288(10):6788-6800.

161. Terabe M, et al. NKT cell-mediated repression of tumor immunosurveillance by IL-13 and the IL-4RSTAT6 pathway. Nat Immunol. 2000;1(6):515-520.

162. Terabe M, et al. A nonclassical non-V $\alpha 14 \mathrm{~J} \alpha 18$ CD1d-restricted (type II) NKT cell is sufficient for down-regulation of tumor immunosurveillance. J Exp Med. 2005;202(12):1627-1633.

163. Theron AJ, Anderson R, Rossouw TM, Steel HC. The role of transforming growth factor $\beta-1$ in the progression of HIV/AIDS and development of non-AIDS-defining fibrotic disorders. Front Immunol. 2017;8:1461.

164. Terabe M, et al. Synergistic enhancement of $C D 8^{+}$ T cell-mediated tumor vaccine efficacy by an anti-transforming growth factor-beta monoclonal antibody. Clin Cancer Res. 2009;15(21):6560-6569.

165 . Terabe $M$, et al. Blockade of only TGF- $\beta 1$ and 2 is sufficient to enhance the efficacy of vaccine and PD-1 checkpoint blockade immunotherapy. Oncoimmunology. 2017;6(5):e1308616.

166. Takaku S, et al. Blockade of TGF- $\beta$ enhances tumor vaccine efficacy mediated by CD8(+) T cells. Int J Cancer. 2010;126(7):1666-1674.

167. Santosuosso M, Righi E, Lindstrom V, Leblanc PR, Poznansky MC. HIV-1 envelope protein gp120 is present at high concentrations in secondary lymphoid organs of individuals with chronic HIV-1 infection. J Infect Dis. 2009;200(7):1050-1053.

168. Rychert J, Strick D, Bazner S, Robinson J, Rosenberg E. Detection of HIV gp120 in plasma during early HIV infection is associated with increased proinflammatory and immunoregulatory cytokines. AIDS Res Hum Retroviruses. 2010;26(10):1139-1145

169. Garg AJ, Spector SA. Myeloid derived suppressor cells (MDSC) from HIV-infected individuals are defective in innate immunity to Mycobacterium tuberculosis thus increasing the risk of tuberculosis. J Immunol. 2019;202(1 suppl):62.

170.Tsiganov EN, et al. Gr- $1^{\mathrm{dim}} \mathrm{CD} 11 \mathrm{~b}^{+}$immature myeloid-derived suppressor cells but not neutrophils are markers of lethal tuberculosis infection in mice. J Immunol. 2014;192(10):4718-4727. 